REPORT OF A CASE OF

\section{MULTIPLE FATTY TUMOURS.}

\section{BY C. C. RICHARDS, M.D., \&c.}

As I believe it is right and proper that all cases of unusual occurrence should be made known to the profession, whether their results be favourable or otherwise, I venture to think the following worthy of record, as a remarkable case in which the body was covered with tumours varying in size from that of a pea to twice the dimensions of a child's head. The case occurred in the practice of Dr. Davies, of Bryngolwg, who, in the operation, had the assistance of Mr. Wilson and myself.

D. M- aged thirty-one years, in appearance stunted and delicate, had been blind from childhood, and got his living by playing a harp at a tavern. Nine days ago he called at the surgery of Dr. Davies to ask advice about a number of tumours studded more or less over the whole of his body, but particularly respecting a very large one situated in the left axilla, and extending from beneath the pectoral muscles in front to the scapula behind, pushing back the scapula to some extent, and surrounding it on its dorsal aspect. From its enormous size and the pressure exercised by it, the arm was kept in a semi-extended position, getting quite atrophied and useless; and, in consequence of the paralysed state of his arm and hand, he had been obliged to give up his occupation as harpist.

In appearance, the tumour itself was covered with a network of varicose veins, and the most pendulous part looked blue and inflamed as if about to slough. To the tonch it felt as if it contained fluid, but upon percussion vibration was not very distinct. However, as he had several tumours on the body elsewhere, varying in size from a walnut to a cocoa-nut, and having all the appearance of fatty tumours, it was thought that the axillary one might be of the same character; so, as his health was evidently suffering from the weight of the tumour, and he was most anxious to have it removed, his wishes were acceded to. There were also two tumours the size of cocoa-nuts on the front of the body, one of which was situated on the front of the right thigh, the other on the left hip ; with a great many smaller ones (from twenty to thirty) over the whole of the abdomen. The back was thickly studded with small tumours the size of beans. He also had a few in the popliteal spaces, one over the coccyx, one of considerable size on the nape of the neck, and another under the right arm ; so that it might be said that he was literally a walking mass of tumours.

On the 20th inst. he came again to the surgery, most anxious to have the axillary tumour removed, as it pained him much ; so in the evening Dr. Davies removed the entire mass, which consisted principally of fat intermingled with fibrous tissue and cartilage. Enclosed in the mass was a large bilocular cyst, which gave way after the skin was removed, and from which about three pints of serous fluid ran out.

There was but little difficulty in detaching the tumour from the surrounding tissues, as two-thirds of it we $\mathbf{s}$ most readily separated with the hand; but its costal attachments were rather firm, though not so firm as to require much use of the knife. However, before the entire mass was detached, a copious oozing of blood took place, when the patient lost from a pint to a pint and a half; and which, doubtless, so lowered him that he never rallied, but sank in about an hour and a half after the operation was completed. That the oozing was general is evident from the fact that it was only necessary to secure one artery, and that the hæmorrhage immediately ceased upon the application of cold water to the parts.

When the tumour was examined, it was found to consist of the before-mentioned tissues; and, without taking into account the fluid which escaped from its eyst, it weighed eight pounds, so that when entire it must have weighed at least eleven pounds. That the tumour is not to be compared in size to some removed, I am well aware (see Cooper's "Surgical Dictionary"); but 1 have not been able to see an account of any person having the body so completely covered with tumour as this poor man (certainly the account of a man introduced by Mr. Saul to the members of the Pathological Society of London is the nearest approach to anything of the kind that I can find); and it is much to be regretted that he was not operated upon sooner, before his health got affected, as I believe he would have recovered from the operation, however long he might have lived afterwards.

Bryngolwg, Aberdare, April 25th, 1865.

\section{FATAL CASE OF EMBOLISM.}

\section{By EDWIN H. ROE, M.R.C.S.}

A. P—, aged forty years, a domestic servant, unmarried, was taken in labour of her first child on January 1st, 1865. The labour was tedious, and in consequence of there being no advance after the os was fully dilated, it was terminated with. out difficulty by the long forceps. The child was alive. The perineum was slightly torn. She complained next day of slight abdominal pain, but there was no tenderness on pressure. The pulse was 100, and small. She continued in a low weak state, though taking brandy and nourishments, until Jan. 25th, when violent griping and purging came on. This was at once relieved by a starch-and-laudanum enema. On the 28th she seemed more cheerful, and said she felt much better; but the pulse was still quick and weak; no pain and no difficulty of breathing. At half-past nine on the same evening, after getting up to the night-chair, she became suddenly agitated, throwing her arms violently about, and exclaiming that she was dying, and also complaining of extreme pain in the belly. The breathing was deep, irregular, and gasping ; she was extremely pale; both fæces and urine were passed under her. At ten P.M. she was dead, becoming quiet and calm shortly before her death.

Autopsy, sixty hours after death. - The pericardium contained about two ounces of clear, straw-coloured fluid. The heart was pale and flabby; both sides were almost empty, there being in each only a small quantity of dark fluid blood. Valves healthy. No clots in any of the cavities. The lungs were crepitant all over; posteriorly there was post-mortem congestion. The main trunk of the pulmonary artery was open, but both the branches contained light-coloured fibrinous clots. On taking hold of one on the right side, a tree-like body was withdrawn; the thickness of the main branch was one-third of an inch, and from this there were four or five branches, the terminal twigs of which were thin, and resembled in appearance ordinary clotted blood. The light-coloured part was tough and elastic, and disposed in concentric layers, not easily separated; some were white throughout, whilst others contained in their interior red clotted blood. There was nothing remarkable about the abdominal organs. The involution of the uterus was complete. No trace of peritonitis. The liver looked somewhat larger than ordinary; but the spleen was normal

This case is interesting, not only from embolism being a disease only lately recognised, but also from the insidious man. ner of its approach; for although the quick and feeble pulse and extreme debility were symptoms by no means to be passed over as of no importance, yet they were attributed rather to the depressing circumstances of her confinement, as she seemed to feel the disgrace of her position very acutely, and was besides of an extremely taciturn disposition. I never examined the heart during life, as there was no complaint at any time of pain or uneasiness in the chest, nor any difficulty of breathing.

Patricroft, 1865

The St. Petersburg Epidemrc. - Some time ago appeared in the Weiner $M e d$. Woch. a letter stating that the St. Petersburg hospitals were closed against foreign medical men, so as to conceal the real nature of the epidemic, sup. posed to be the Siberian plague. This assertion has been flatly contradicted by Dr. Van Corput, a delegate of the Belgian government. This physician sent a letter to the Journal of St. Petersburg, stating that the greatest courtesy is shown to visitors, that every facility is given for investigating the complaint, and that the latter, far from being the Siberian plague, is, as reported, relapsing fever, with some cases of typhus.

Dratu of Prof. Reveil.-Dr. Reveil was one of the most promising scientific chemists of Paris, attached as assistant professor both to the Faculty of Medicine and the School of Pharmacy. He died suddenly at a nursery garden in Versailles, where he was ordering flowers for a family party, at the age of forty four. The deceased may be said to have died of orerwork, as the public and courts of law placed the most implicit confidence in him as an analytical chemist. Dr. Réveil obtained all his appointments by competition, and was an indefatigable labourer in the branch of science he had chosen. He published many works, and quite lately a translation of Mr. Piesse's book on perfumes. 